\title{
Validation of a Theoretical Model for the Correction of Heat Transfer Effects in Turbocharger Testing through a Quasi-3D Model
}

Silvia Marelli Universita Degli Studi di Genova

Gianluca Montenegro, Matteo Tamborski, and Augusto Della Torre Politecnico di Milano

Citation: Marelli, S., Montenegro, G., Tamborski, M., and Della Torre, A., "Validation of a Theoretical Model for the Correction of Heat Transfer Effects in Turbocharger Testing through a Quasi-3D Model," SAE Technical Paper 2020-01-1010, 2020, doi:10.4271/2020-011010.

\section{Abstract}

$\mathrm{n}$ the last few years, the effect of diabatic test conditions on compressor performance maps has been widely investigated, leading some Authors to propose different correction models. The accuracy of turbocharger performance map constitute the basis for the tuning and validation of a numerical method, usually adopted for the prediction of engineturbocharger matching. Actually, it is common practice in automotive applications to use simulation codes, which can either require measured compression ratio and efficiency maps as input values or calculate them "on the fly" throughout specific sub-models integrated in the numerical procedures. Therefore, the ability to correct the measured performance maps taking into account internal heat transfer would allow the implementation of commercial simulation codes used for engine-turbocharger matching calculations.

In the paper the main results of a wide experimental activity are reported to provide a general understanding of heat transfer mechanism occurring in turbochargers and relationships for heat transfer rate useful to derive the adiabatic efficiency. The compressor steady flow performance maps were measured at different operating temperatures for compressor and turbine, with and without water-cooling and under quasi-adiabatic condition achieved by maintaining the lubricating oil average temperature equal to compressor outlet temperature and turbine inlet temperature to minimize internal heat fluxes. Furthermore, a mathematical model for the correction of compressor steady flow maps, developed by the University of Genoa, is adopted and compared to the quasi-adiabatic condition. In the context of this work a quasi-3D CFD code developed at Politecnico di Milano has been extended and applied to simulate the flow inside the compressor. To this purpose the adiabatic assumption has been removed and the heat transfer between the gas and the stationary and rotating components has been taken into account. Correlations for the heat transfer coefficient have been taken from the literature and implemented in the code. The quasi-3D model is then used to simulate the compressor both in adiabatic and diabatic condition. The quasi-3D CFD code was validated against the experimental results, confirming also the validity of the mathematical model used to correct the maps.

\section{Introduction}

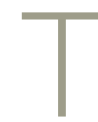

urbocharging technology is today a key solution to solve the reduction of exhaust emissions and fuel consumption, along with other strategies such as engine downsizing, fully flexible intake valves control, and Direct Injection in automotive gasoline engines $[1,2]$. The improvement of turbocharger-engine matching calculation can be achieved through an accurate measurement of turbine and compressor maps properly accounting for the heat transfer processes associated to the experimental test. In a diabatic process or test, the machine total enthalpy change is the sum of the work and of the heat transfer rates. The accurate measurement of the adiabatic work transfer and efficiency of compressor and turbine (avoiding internal and external heat transfer rates) can be obtained through adiabatic test. However, the high costs linked to testing facilities often discourages efforts on this topic. Therefore, manufacturer maps generally consider the turbocharger process to be adiabatic.

A number of Researchers focus their studies on the effect of heat transfer in compressor map, considering a modelling approach to correct efficiency measured performance $[\underline{3}, \underline{4}, \underline{5}$, 6]. The model, here adopted for the correction of compressor maps and proposed by Marelli et al. in $[\underline{7}, \underline{8}]$, is characterized by the easiness of data post-processing, the database economy, the limited number of geometrical and physical information. The compressor adiabatic efficiency can be calculated starting from the experimental maps affected by the heat transfer. Therefore, corrected compressor maps allow estimating a more reliable adiabatic compressor power, therefore the adiabatic compressor efficiency.

The total-to-total isentropic compressor efficiency can be expressed as 


$$
\eta_{c T T}=\frac{P_{c i s}}{P_{c}}=\frac{M_{c} \cdot c_{p c} \cdot\left(T_{T 2 i s}-T_{T 1}\right)}{M_{c} \cdot c_{p c} \cdot\left(T_{T 2}-T_{T 1}\right)}
$$

where:

$M_{c}$ is the compressor mass flow rate;

$\mathrm{C}_{\mathrm{pc}}$ is the specific heat at constant pressure referred to compressor;

$\mathrm{T}_{\mathrm{T} 1}$ is the compressor inlet total temperature;

$\mathrm{T}_{\mathrm{T} 2 \mathrm{is}}$ is the compressor outlet total temperature for an isentropic process;

$\mathrm{T}_{\mathrm{T} 2}$ is the compressor outlet total temperature.

If the compressor working condition is not adiabatic, Equation (1) leads to an unrealistic measurement of compressor efficiency, which results underestimated due to the overestimation of the measured outlet temperature, for example.

The correction model allows to take into account the heat transfer internal to the turbocharger, if it is not available a proper measurement of the term $\mathrm{Q}_{\mathrm{int}}$, which represents a net conductive heat transfer driven to the compressor thorough the bearing housing (see eq. 2):

$$
\eta_{c T T}=\frac{P_{c i s}}{P_{c}}=\frac{M_{c} \cdot c_{p c} \cdot\left(T_{T 2 i s}-T_{T 1}\right)}{M_{c} \cdot c_{p c} \cdot\left(T_{T 2}-T_{T 1}\right)-Q_{i n t}}
$$

where:

$\mathrm{P}_{\text {cis }}$ is the isentropic compressor power;

$\mathrm{P}_{\mathrm{c}}$ is the real compressor power;

$\mathrm{M}_{\mathrm{c}}$ is the compressor mass flow rate;

$\mathrm{C}_{\mathrm{pc}}$ is the specific heat at constant pressure referred to compressor;

$\mathrm{T}_{\mathrm{T} 1}$ is the compressor inlet total temperature;

$\mathrm{T}_{\mathrm{T} 2 \mathrm{is}}$ is the compressor outlet total temperature for an isentropic process;

$\mathrm{T}_{\mathrm{T} 2}$ is the compressor outlet total temperature.

In a previous paper [9], the authors followed a different approach measuring the heat transfer internal to the turbocharger to provide a general understanding of heat transfer mechanism occurring in turbochargers and relationships for heat transfer rate useful to derive the real diabatic efficiency. Based on the results of infrared thermal inspections, a novel procedure to evaluate the internal heat transfer from the turbine to the compressor has been developed and the good quality of results has been confirmed by comparing efficiency maps during diabatic tests with the quasi-adiabatic ones when the measured internal heat flow has been accounted for. The estimated heat flux has been adopted as a boundary condition for the quasi-3D model used to predict the compressor performance (pressure ratio and efficiency) in diabatic conditions.

The numerical model here adopted is a quasi-3D CFD solver developed by the authors at Politecnico di Milano and used for research purposes. The approach is a map-less method based on a quasi-3D reconstruction of the compressor, and was originally developed to model the acoustic and fluid dynamic behavior of complex shape devices in the intake and exhaust systems of internal combustion engines $[10,11,12$, $\underline{13}, 14]$ and then extended to the modeling of compressors [14]. In this work, the approach has been furtherly extended considering the heat transfer effects between the compressor components and the gas flowing in the turbomachine. The solution on the quasi-3D domain is calculated for each operating condition, then suitably coupled to a 1D model (developed in gasdyn) to replicate the upstream and downstream pipe system and to handle the imposition of boundary condition on the basis of consolidated numerical approaches. The validity of the mathematical model used to correct the maps was confirmed by the quasi-3D model used to simulate the compressor both in adiabatic and diabatic condition and validated against the experimental results.

\section{Experimental Equipment and Testing Procedure}

To highlight the effect of different boundary conditions on heat transfer phenomena, a wide experimental campaign was developed at the University of Genoa test rig $[\underline{8}, \underline{15}]$. The facility, schematically shown in Figure 1, consists of a compressed-air equipment able to perform investigations on intake and exhaust automotive components under both steady and unsteady flow conditions. Three screw compressors supply a total mass flow rate of $0.6 \mathrm{~kg} / \mathrm{s}$ at a maximum pressure of 8 bar. Experimental investigations can be performed in "cold" and "hot" conditions by properly selecting the thermal power provided by an electrical air heating station that allows the increase of turbine inlet temperatures up to $750{ }^{\circ} \mathrm{C}$.

Turbocharger performance is measured over an extended range by independently control the upstream pressure of turbine and compressor circuits. In the case of investigation on the compressor side, the measurement of performance maps starts from the choking zone to the surge line changing the external circuit characteristic curve through a motorized throttle valve (Figure 1) and controlling the turbine work output properly. An automatic data

FIGURE 1 The turbocharger test facility at the University of Genoa.

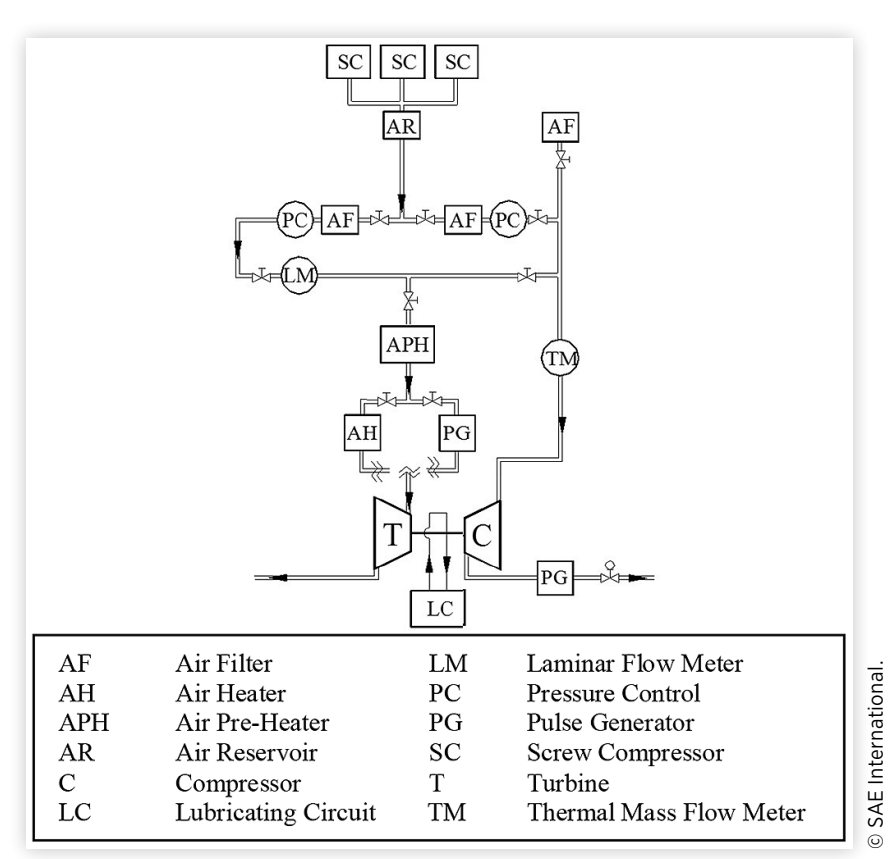


acquisition system allows measurements of thermodynamic parameters at different measuring sections to be recorded. To evaluate compressor efficiency with good accuracy, three different pressure wall taps and three temperature probes (circumferentially located at $120^{\circ}$ ) are used. The static pressures are measured through strain-gauge and piezoresistive transducers characterized by an accuracy of $\pm 0.15 \%$ of the full scale. A high frequency response pressure sensor used to monitor the surge phenomenon is installed close to the wall downstream of the compressor [16]. The air temperature levels are measured through platinum resistance thermometers (Pt $100 \mathrm{Ohm}$, accuracy of $\pm 0.15^{\circ} \mathrm{C}+0.2 \%$ of measured value) or $\mathrm{K}$ type thermocouples (accuracy $\pm 1.5{ }^{\circ} \mathrm{C}$ ). The turbocharger rotational speed is measured by an inductive probe mounted close to the compressor wheel allowing to detect rotor revolution with an accuracy of $\pm 0.009 \%$ of full scale. Compressor mass flow rate is measured through a thermal mass flow meter with an accuracy of $\pm 0.9 \%$ of measured value and $\pm 0.05 \%$ of the full scale. During compressor performance tests, the distribution of the external surface temperature of the turbocharger has been recorded using wall thermocouples $[\underline{8}, \underline{9}]$. Besides, measurements performed at low temperature levels are supported by thermal imaging to monitor external surface temperatures on turbocharger. Turbocharger surface is lacquered with experimentally evaluated emissivity color.

The experimental investigation was developed on a small automotive turbocharger fitted with a single-entry, nozzle-less radial flow turbine (maximum impeller diameter $33 \mathrm{~mm}$ ) and a centrifugal compressor (maximum impeller diameter of 40 $\mathrm{mm}$ ), matched to a downsized 4 cylinder, Spark Ignition engine.

The experimental compressor maps are referred to the commonly adopted parameters properly scaled on the conventional non-dimensional groups.

The experimental activity was conducted by keeping the turbine inlet temperature fixed at $80,300,600$ and $900^{\circ} \mathrm{C}$ and taking into account the following operating conditions: total inlet pressure of 1 bar for the compressor corrected rotational speeds of 59000, 89000, 118000, and $162000 \mathrm{rpm}$. The influence of turbine inlet temperature, the possible presence of water-cooling characterized by different inlet temperature levels and the lubricating oil temperature were taken into account to study the influence of the heat flux from turbine and oil casings to compressor side []. Moreover, additional experiments were accomplished under quasi-adiabatic condition, i.e., maintaining the average oil temperature equal to compressor outlet temperature and turbine inlet temperature $\left(\mathrm{T}_{\text {oil_mean }}=\mathrm{T}_{\mathrm{T} 2}=\mathrm{T}_{\mathrm{T} 3}\right)$. Due to the highest level of turbine inlet working temperature (about $600^{\circ} \mathrm{C}$ ), the quasi-adiabatic condition was performed keeping the water-cooling and the average lubricating oil temperature equal to compressor outlet temperature $\left(\mathrm{T}_{\mathrm{WC}}=\mathrm{T}_{\text {oil_mean }}=\mathrm{T}_{\mathrm{T} 2}\right)$. Both methods adopted to perform quasi-adiabatic test proved to be similar resulting in comparable characteristic curves. It must be remarked that quasi-adiabatic characteristic curve was not measured at the highest level of turbocharger rotational speed due to difficulties related to high oil temperature level requested. However, the lack of information is less important since the heat transfer effect is more prominent at lower level of turbocharger rotational speed.

\section{Heat Transfer Correction Model}

A mathematical model, developed by the University of Genoa and fully described in []ㅡ, for the correction of compressor steady flow maps is adopted and compared to the quasi-adiabatic condition. Besides, the quasi-3D model is used to simulate the turbocompressor both in adiabatic and diabatic condition and validated against the experimental results, confirming the validity of the mathematical model used to correct the maps. When the compression process is not adiabatic, a heat flux has to be taken into account to correctly evaluate compressor efficiency with special reference to a diabatic efficiency, which contains the specific rate of heat exchange, generally quite difficult to be assessed without a conjugate heat transfer model, which needs an entire thermal characterization of the turbocharger. The model developed by the University of Genoa allows to evaluate adiabatic performances of a compressor by means of a simplified approach to be applied to experimental efficiency maps available (provided by turbocharger manufacturer or directly measured). In Figure 2 the flowchart of the model, here briefly described, is shown.

Different iso-speed characteristic curves are compared in terms of work and flow coefficients, assuming that the geometrical impeller outlet angle is strictly constant over the whole compressor map. The procedure is founded on the comparison among impeller outlet angle values obtained at different rotational speed levels. The velocity triangle at the impeller outlet is determined considering the slip velocity on the basis of Stanitz expression, suitable for a wide range of backswept impeller. The estimation of both tangential and meridian components of flow velocity at impeller outlet section allows the evaluation of impeller outlet angle. Starting from compressor mass flow rate, blade and diffuser height and flow density at the impeller outlet, the meridian velocity is calculated. A recovery model is needed to step backward to the impeller outlet starting from downstream compressor measuring section through the volute and the diffuser. Therefore, recovery factors for the volute and for the diffuser are adopted, with reference to the correlation of Eynon and Whitfield [17] and Sovran and Klomp maps with a much easier method [18]. An iterative procedure is used for both recovery factors parameters referring to the upstream compressor thermodynamic conditions. The impeller Eulerian work coefficient, as proposed by Sirakov and Casey in [19], allows to calculate the tangential velocity. The Eulerian work input can be calculated subtracting the disk friction losses, evaluated through theoretical and empirical correlations proposed by Daily and Nece [20] from the real compression work. This assumption is feasible at the design point (i.e., when other losses contribution is substantially constant at different rotational speed) and assuming a quasi-adiabatic compression process. The heat exchange is simplified in a conduction term related to a constant heat transfer and the temperature difference between compressor volute and bearings housing surfaces under the hypothesis that the heat flux into the compressor is mainly due to the temperature difference 
FIGURE 2 Correction model numerical iteration procedure flowchart.

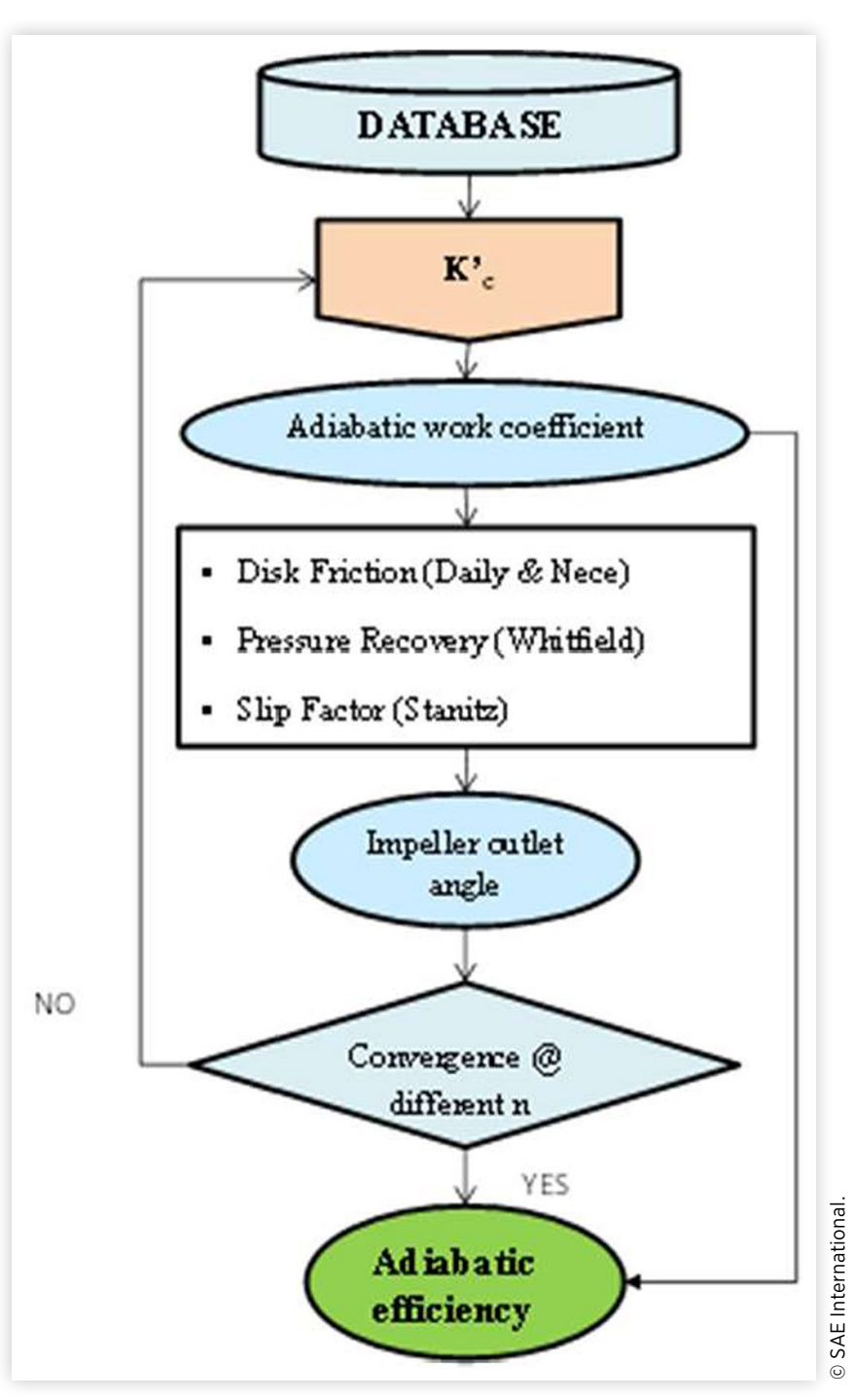

between the compressor and the lubricant casing. The parameter kc', defined as the ratio between the constant heat transfer and the impeller diameter, is strictly constant throughout the map for a fixed turbocharger unit, since it depends only on geometrical terms. Even if $\mathrm{kc}$ ' is usually quite difficult to be determined, it is used as a convergence coefficient for the whole map, starting from a first guess value. The heat contribution was taken into account also for the evaluation of flow density at the impeller outlet. The work and heating flux coefficients are evaluated thorough a numerical iteration procedure based on $\mathrm{kc}^{\prime}$ and impeller outlet angle values. The final value of kc' is then adopted to determine the adiabatic work coefficient and therefore the adiabatic efficiency.

Figure 3 shows the compressor total-to-total efficiency map for different values of corrected compressor rotational speed. Continuous black curves represent efficiency values measured in real quasi-adiabatic conditions, whereas symbols and continuous lines indicate the efficiency values measured in real diabatic conditions. Deviations from the quasi-adiabatic condition of each curves (recorded at a constant level of
FIGURE 3 Comparison between diabatic, quasi-adiabatic and corrected compressor efficiency maps without water cooling.

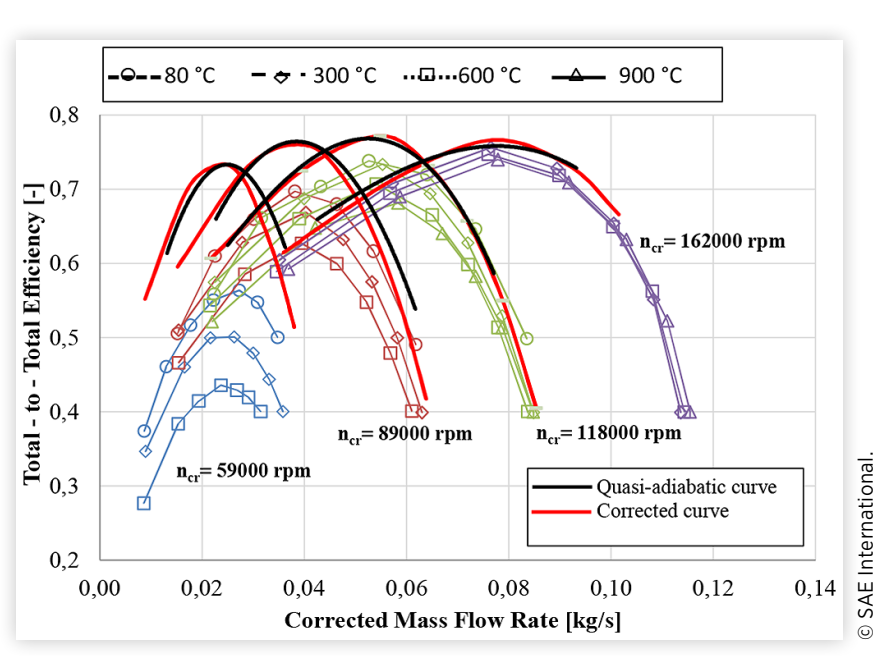

FIGURE 4 Comparison between diabatic and quasiadiabatic and compressor pressure ratio maps without water cooling.

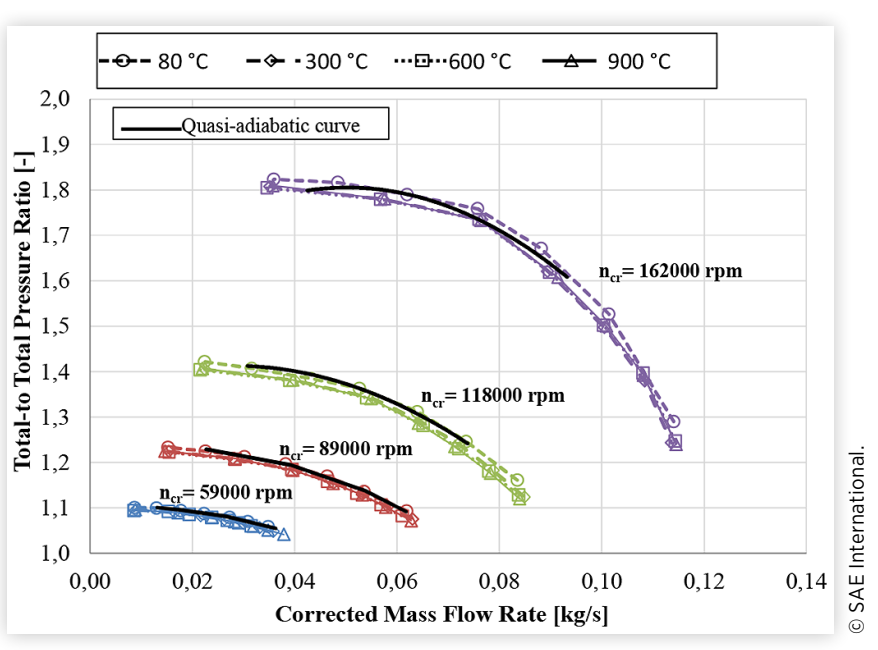

rotational speed) reflect the heat transfer effects, which are more prominent at the lowest turbocharger rotational speeds, where efficiencies appear to be markedly underestimated. The temperature difference between the compressor and the turbine side decreases and compressor efficiency curves progressively approach the adiabatic curves when the rotational speed is increased. In particular, heat transfer effects do not affect the efficiency evaluation at the highest rotational speed $\left(\mathrm{n}_{\mathrm{cr}}=162000 \mathrm{rpm}\right)$. It must be highlighted that at the lowest level of turbocharger rotational speed and at the highest level of turbine inlet temperature (equal to $900^{\circ} \mathrm{C}$ ), it was not possible to perform experimental measurements due to oil over temperature issues. By comparing the corrected maps (red continuous lines in Figure 3) with the quasi-adiabatic curves, a satisfactory result is highlighted, resulting in a suitable approach followed by the correction model.

To highlight the impact of heat transfer on compressor pressure ratio maps, in Figure 4 the total-to-total pressure 
ratio is plotted versus corrected mass flow rate considering the turbine inlet temperature ranged from 80 to $900{ }^{\circ} \mathrm{C}$, without the presence of water-cooling and maintaining the oil inlet temperature at about $80^{\circ} \mathrm{C}$. Compressor maps can be compared with the corresponding quasi-adiabatic curves, highlighting that the heat transfer seems to have less impact on pressure ratio characteristic curves. Since compressor characteristic curves were measured in two different test facilities as reported in []ㅛ, slight differences can be observed between each curve probably due to moderate differences on measuring equipment adopted. However, deviations could be neglected because of slight entity.

\section{CFD Model}

The quasi-3D approach adopted in this work consist of reproducing the 3D geometry as a network of $0 \mathrm{D}$ elements, called cells, connected by them by means of other elements, called connectors or ports.

As shown in Figure 5, the quasi-3D domain is defined by means of two fundamental elements: the cell and the port. The cell element is defined by its volume (as a mere property, being the cell a $0 \mathrm{D}$ element) and by the list of the ports it is connected to. The port element is mainly a $1 \mathrm{D}$ element arbitrarily oriented in the space: it defines geometric parameters such as the shape of the cells it is connected to, the distance from the adjacent cell centres, the direction with respect to an absolute orientation system and the flow area. Additional information stored in cells and ports may appear for every specific case where they differ from the standard ones (i.e. peripheral velocity appear in rotating cells, while it is not present in simple fluid cells). Combining these two elements, it is therefore possible to approximate a real 3D shape as a network of $1 \mathrm{D}$ and $0 \mathrm{D}$ element suitably connected, reducing in this way three-dimensional geometry to a system of $1 \mathrm{D}$ equations along the direction of the normal of the port surfaces.

From the physical point of view, the quasi-3D model is based on the formulation of the conservation equations of mass, momentum and energy for unsteady and compressible flows. Although it is derived from the Navier-Stokes equations, in the actual context, the set of equations relies on the inviscid flow assumption. Also, the effect of thermal diffusivity has

FIGURE $\mathbf{5}$ Example of cells and ports network.

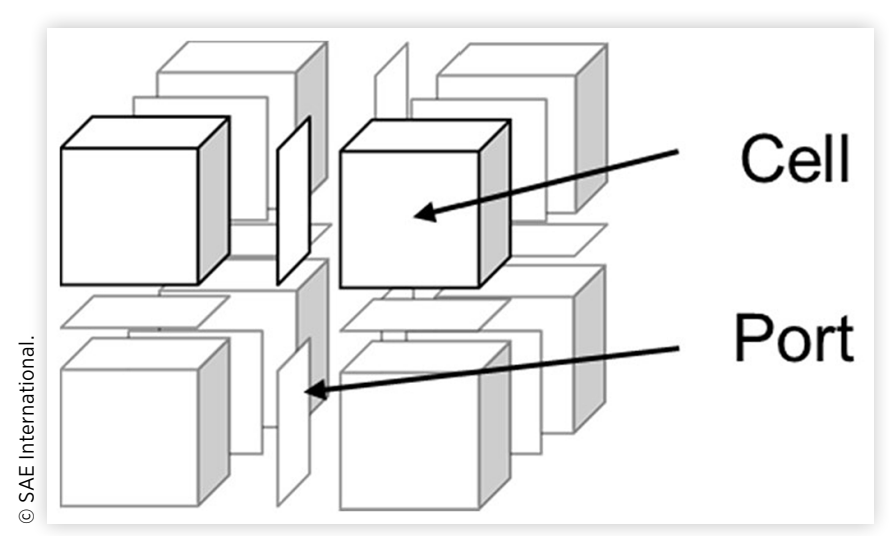

not been considered. These approximations are acceptable for highly turbulent flow regimes where the inertial effects are prevailing over the viscous ones and when convection prevails against diffusion, leading in this way to the Euler set of equations:

$$
\begin{gathered}
\frac{\partial(\rho \vec{v})}{\partial t}+\nabla \cdot(\rho \vec{v} \vec{v})=-\vec{\nabla} p+\overrightarrow{\mathrm{F}}+S_{M} \\
\frac{\partial(\rho e)}{\partial t}+\nabla \cdot(\rho h \vec{v})=S_{e} \\
\frac{\partial \rho}{\partial t}+\nabla \cdot(\rho \vec{v})=0 .
\end{gathered}
$$

The set of PDEs is then closed with the equation of state of perfect gas, which links the density to pressure and temperature of the gas considering the compressibility.

From a numerical point of view, the set of PDEs is discretized over a space domain on the basis of a staggered approach, in which intensive proprieties like density, internal energy, and other derived quantities, are evaluated in the $0 \mathrm{D}$ elements, whereas velocity and momentum, are defined in the 1D elements (see Figure 6).

Based on these considerations the discretized equations are solved with respect to different control volumes. The integration of the momentum equation is performed referring to a control volume defined by the port surface $A$ and by the distance $\Delta L$ between the two-neighbouring cell centres, as shown in Figure 7.

According to this definition, the momentum equation (eq. 6) is solved at port level:

$$
\begin{aligned}
(\rho \vec{v} A)_{\text {port }}^{t+\frac{1}{2}}= & (\rho \vec{v} A)_{\text {port }}^{t-\frac{1}{2}} \\
& +\frac{\Delta t}{\Delta L} A_{\text {port }}\left[\left(p+\rho v_{n}^{2}\right)_{L}^{t}-(p+\rho v)_{R}^{t}\right]+S_{M} .
\end{aligned}
$$

From this equation the volumetric flux is then computed and used in the mass and energy conservation equations (eqns. 7 and $\underline{8}$ ) to determine the net balance of mass and energy entering every single cell of the domain:

\section{FIGURE 6 Properties defined on cells and ports.}

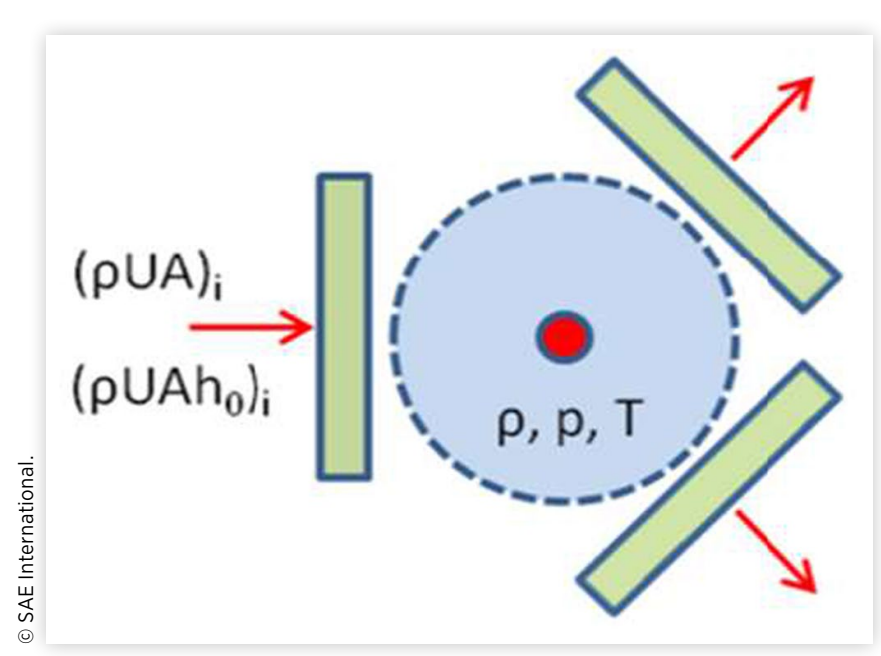


FIGURE 7 Control volume of momentum equation.

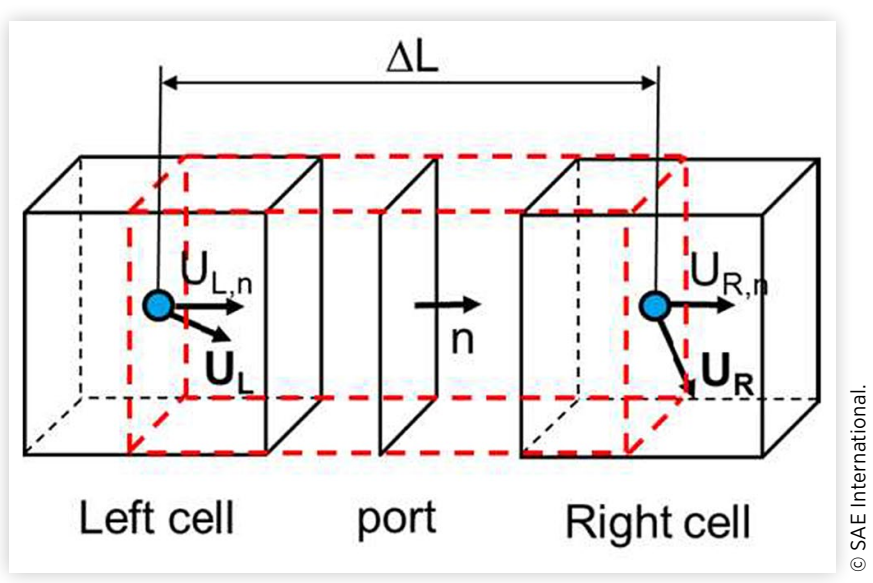

$$
\begin{gathered}
\rho_{\text {cell }}^{t+1}=\rho_{\text {cell }}^{t}+\frac{1}{V} \sum_{p=1}^{N_{\text {ports }}}(\rho v A)_{p}^{t+\frac{1}{2}} \Delta t \\
\left(\rho e^{0}\right)_{\text {cell }}^{t+1}=\left(\rho e^{0}\right)_{\text {cell }}^{t}+\frac{1}{V} \sum_{p=1}^{N_{\text {ports }}}\left(\rho v h^{0} A\right)_{p}^{t+\frac{1}{2}} \Delta t+S_{e}
\end{gathered}
$$

The solution procedure adopted to solve the Euler set of equations is the explicit time marching staggered leapfrog method. It follows that the fluxes at the ports are computed in an intermediate time step with respect to mass and energy solved in the cells. Therefore, three different time levels are defined $(t, t+1 / 2$ and $t+1)$ over which the three conservation equations are suitably defined. The pseudo-staggered arrangement in space and the explicit time marching staggered leapfrog method in time confer the model a second order accuracy both in space and time.

Equations 6-8 express the conservation laws for fluid cells and port without any particular modelling assumption. These equations have source terms $S_{e}$ and $S_{m}$ to consider specific sources based on the type of components that are addressed. For instance, the momentum equation can be contributed with a source term representing the flow resistance due to the presence of gas-wall friction, or the energy equation can be similarly modified to consider the heat flux due to the convective heat transfer between the gas and the wall. In the case of the modelling of the compressor, the set of equations is modified to consider the presence of rotating parameters, of heat transfer inside the rotor and the volute, of friction in the rotor, diffuser and volute, and finally to consider the Eulerian work exchanged between the gas and the fluid machine.

Therefore, the compressor has been divided into different regions; each one treated numerically in a different way (see Figure 8):

- the inlet region, where the flow is taken for the ambient, or from an external 1D domain suitably coupled, and then distributed to the different channels of the impeller (blue region in Figure 8);

- the impeller region, where the flow exchanges work with the rotating parts. The inlet ports will have the surface
FIGURE 8 Set of regions used to divide the compressor. Each region is numerically treated in a different way.

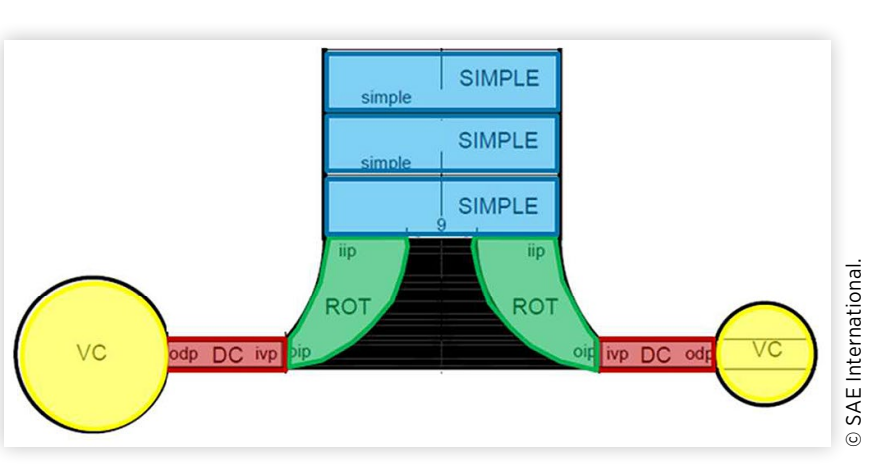

normal directed as the inlet blade angle, (green region in Figure 8);

- the vaneless diffuser, where the pressure recovery occurs thanks to the increase of the flow section in the radial direction (red region in Figure 8);

- the volute, where the compressed air is collected and delivered to the outlet pipe (yellow region in Figure 8).

\section{Model of the Inlet Region}

The inlet region is modelled as a $1 \mathrm{D}$ pipe, where source terms are included to take into account the gas-wall friction, the heat transfer between the gas and the walls and the effect of flow area change. Therefore, the conservation equations of momentum and energy become as follows:

$$
\begin{aligned}
(\rho \vec{v} A)_{\text {port }}^{t+\frac{1}{2}}= & (\rho \vec{v} A)_{\text {port }}^{t-\frac{1}{2}} \\
& +\frac{\Delta t}{\Delta L} A_{\text {port }}\left[\left(p+\rho v_{n}^{2}\right)_{L}^{t}-\left(p+\rho v_{n}^{2}\right)_{R}^{t}\right]-F .
\end{aligned}
$$

The source term $F$ is a function of the mass flow and of a friction coefficient $f_{\text {coeff }}$ :

$$
F=(\rho \vec{v} A)_{\text {port }}^{t+\frac{1}{2}}\left|\vec{v}_{\text {port }}\right| f_{\text {coeff }} \frac{2}{d_{h, \text { port }}}
$$

where $d_{h \text {,port }}$ is the equivalent diameter of the port, i.e. the diameter of a port with same cross-sectional area but with circular shape.

The friction coefficient is evaluated resorting to the formula proposed by Swamee and Jain [21] for pipe with circular section and with a relative roughness $10^{-6}<\mathrm{k} / \mathrm{D}<10^{-2}$. In the impeller channels and in the vaneless diffuser, the friction coefficient is corrected to take into account that their cross sections do not fit the circular-shape assumption of the original formulation. In addition, extra sources of friction are present in these regions, e.g. pressure-induced secondary eddies, Coriolis eddies, trailing edge losses, and a surface in sliding motion on top of the rotating channels. Both these geometrical and kinematical deviations are assumed to be a function of the flow rate, thus grouped as a corrective 
coefficient $c_{f, \text { corr }}=1,5$ that scales the Swamee and Jain friction coefficient.

\section{Model of the Impeller}

The impeller is discretized as an ensemble of rotating pipes. The choice made in this case is to refer to a relative reference framework, solving the momentum equation with respect to the relative velocity $\vec{w}$. For each rotating port, the surface normal is directed as the-blade profile at that corresponding edge. In this way the velocity computed at that port, and the one referred to the owning or neighbouring rotating cell, corresponds to the relative one. The relation that holds in this case is the following:

$$
\vec{v}=\vec{w}+\vec{u},
$$

Where

$$
\vec{u}=\vec{\omega} \times \vec{r} .
$$

The channels of the impeller are discretised throughout single rotating cells (identified as ROT). Every rotating cell is connected to two ports, namely the inlet impeller ports (IIP) and the outlet impeller port (OIP). All the inlet impeller ports have the same neighbouring cell belonging to the inlet pipe. For this reason, no particular treatment to consider the rotation is adopted at this level, since the fluid dynamic state to which these parts are faced is the same for all of them (1D case).

Therefore, the momentum conservation equation for the inlet impeller port is written as a function of the relative velocity component and takes into account the contribution of the area variation of the blade channel $\left(p^{*} \frac{d A_{\text {port }}}{d x}\right)$ and of centrifugal force field acting on the fluid $\left(\vec{F}_{c} \cdot \vec{n}_{\text {rad }}\right) A_{\text {port }}$, as follows:

$$
\begin{aligned}
(\rho \vec{w} A)_{\text {port }}^{t+\frac{1}{2}}= & (\rho \vec{w} A)_{\text {port }}^{t-\frac{1}{2}}+\frac{\Delta t}{\Delta L} A_{\text {port }}\left[\left(p+\rho w_{n}^{2}\right)_{L}^{t}-\left(p+\rho w_{n}^{2}\right)_{R}^{t}\right] \\
& +\left(\vec{F}_{c} \cdot \vec{n}_{\text {rad }}\right) A_{\text {port }}+p^{*} \frac{d A_{\text {port }}}{d x}
\end{aligned}
$$

At the impeller inlet, incidence losses are also considered when the relative velocity is not angled with the same direction of the blade. This happens in off design conditions, where two possible cases can occur: the relative velocity has a higher angle of incidence or a lower angle of incidence with respect to the blade direction. In Figure 9 the two different off-design flow conditions are highlighted. More specifically, for the two cases, the $W_{n}$ is the one adopted in the balances associated with the port (mass, momentum and energy), whereas the $W^{\prime}$ component is the one that is lost, therefore contributing to the incidence losses.

The model is able to account for the incidence losses, since it considers the projection of the relative velocity $(\vec{w})$ onto the direction of the leading edge, namely the design condition. When the operating condition is off-design only the projection on the blade direction of the relative velocity is considered $\left(w_{n}\right)$. This allows to account for a different energy level when the total energy is conserved in the rotor. It means that the
FIGURE 9 Two different off-design conditions where the relative flow angle at the inlet of the impeller is different form the blade angle at the leading edge.

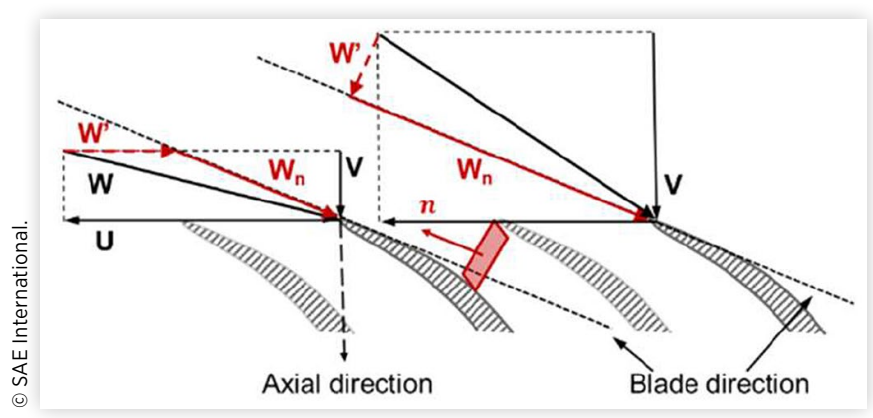

difference between the two relative kinectic energy (design and off-design) is the component that is dissipated. The effect of entropy increase is then mimicked adding an enthalpy variation to the energy equation that is proportional to this loss. The contribution of this additional source terms has been evaluated following what has been proposed in [28]:

$$
\Delta h^{0}=c_{i n c} \frac{\Delta w^{2}}{2}
$$

where $c_{i n c}=0.4$ is a constant, and $\Delta w=w-w_{n}$ is the difference between the relative velocity at the inlet of the impeller $w$ and its component along the blade direction $w_{n}$.

A different approach is adopted for the outlet impeller ports, since they are connected with different cells of the volute, or of the vaneless diffuser due to the rotation. Figure 10 shows how the vaneless diffuser and the volute are discretized: along the circumferential direction the number of cells is

\section{FIGURE 10 Connectivity of the rotor cell with the cells of} the volute/diffuser. A maximum of one to two connection is reached.

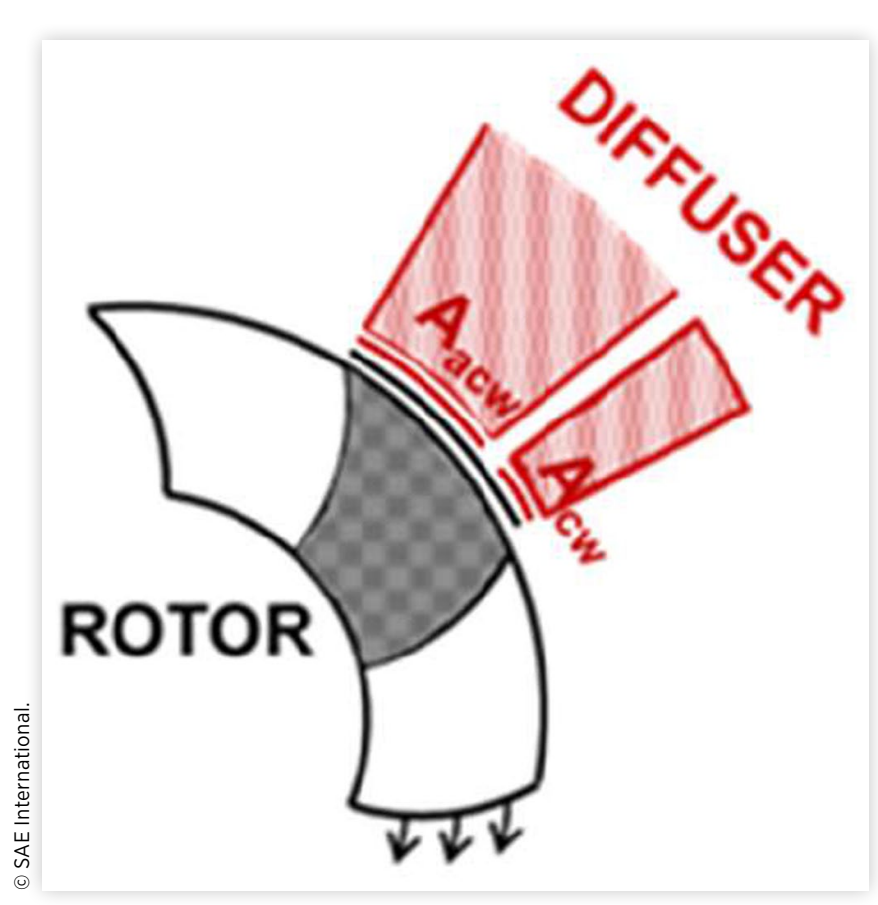


FIGURE 11 Deviation of the flow angle with respect to the blade angle at the trailing edge of the impeller due to the slip effect.

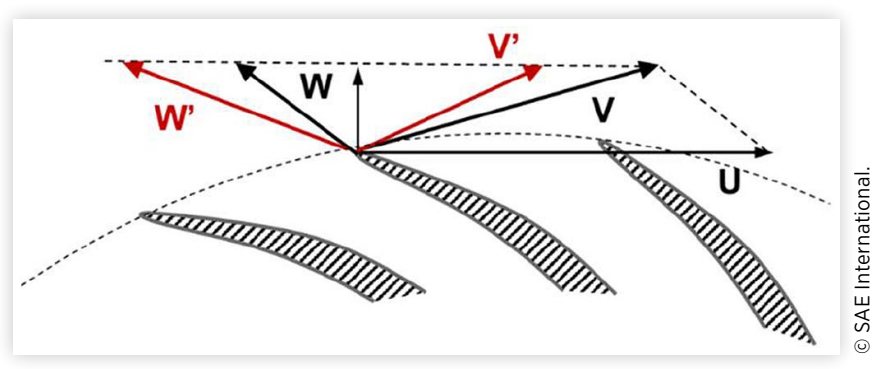

equal between the rotor and the volute, or diffuser, realizing in this a one to one matching. As the rotor moves the connectivity between the rotor cells and the volute cells changes reaching a one-to-two ratio. This means that during the rotation of the impeller the outlet impeller ports can have no more than two neighbouring cells belonging to the diffuser.

Since the solution of the momentum equation requires the calculation of the overlap between ports belonging both to the impeller and to the vaneless diffuser ports, at each iteration, the impeller is rotated around its-axis and, consequently, the cells of the rotor, along with the outlet impeller ports, are moved of the same angular rotation. Based on the number of circumferential meshes, it is possible to know the portion of overlap of one impeller port with the port of the diffuser. The exchange of momentum is, therefore, proportional to the fraction of overlapping area between the impeller and the diffuser. Momentum equation is then solved in each outlet impeller according to the following equation:

$$
\begin{aligned}
(\rho \vec{w} A)_{\substack{o i p \\
a c w}}^{t+\frac{1}{2}}= & (\rho \vec{w} A)_{o i p}^{t-\frac{1}{2}} \cdot\left(\begin{array}{c}
\% A_{o i p} \\
a c w
\end{array}\right)+\frac{\Delta t}{\Delta L} A_{\text {oip }}\left[\left(p+\rho w_{n}^{2}\right)_{L}^{t}\right. \\
& \left.-\left(p+\rho v w_{n}^{2}\right)_{R}^{t}\right]+\left(\vec{F}_{c} \cdot \vec{n}_{\text {rad }}\right) A_{\text {oci }}+A^{*} \frac{d A_{\text {oip }}}{d x} .
\end{aligned}
$$

Once the relative velocity is known, the absolute velocity at the impeller outlet port can be obtained by vectorial composition with the peripheral velocity of the blade. However, before using the kinematic quantities to evaluate the Eulerian work and to determine the flux of energy and mass leaving, or entering, the rotor cells, slip factor is considered to correct the flow angle with respect to the blade angle at the trailing edge, as shown in Figure 11.

Therefore, to mimic the effect of the slip, the Stanitz's equation has been adopted in the calculation model to correct the velocity triangle at the outlet impeller port. The Stanitz's model states that the slip velocity depends on the blade exit angle according to the following equation:

$$
\sigma=1-\frac{1.98}{z\left(1-\frac{v_{2, \mathrm{rad}}}{u_{2}} \operatorname{cotg} \beta_{2}\right)}
$$

where, $z$ is the number of blades, $\beta_{2}$ varies from 90 to $135^{\circ}$ and $\sigma$ is the ratio between the real $\left(W^{\prime}\right)$ and ideal $(W)$ projection of the relative velocity along the direction of the peripheral velocity. The choice of the correlation was also dictated by the need of adopting a correction consistent with the one used in the experimental campaign.

\section{Energy Balance of the Rotor}

After having determined the velocity triangles at the inlet and at the outlet of the rotor (inlet and outlet ports), the relative velocity is used to calculate the fluxes of energy and mass for the rotor cell. In particular, the energy balance at the rotor cells becomes:

$$
\left(\rho e^{0}\right)_{\text {cell }}^{t+1}=\left(\rho e^{0}\right)_{\text {cell }}^{t}+\frac{1}{V} \sum_{p=1}^{N_{\text {ports }}}\left(\rho v h^{0} A\right)_{p}^{t+\frac{1}{2}} \Delta t+S_{e}+S_{\text {heat }}
$$

This balance equation at the rotor cell accounts for the net contribution of the enthalpy flux associated to the relative velocity component at the connected ports (impeller outlet and inlet) and then accounts for the contribution of the work of the centrifugal forces $\left(S_{e}\right)$.

The heat transfer between the fluid and the walls of the compressor is modelled as a source term $S_{\text {heat }}$ in the equation of conservation of energy:

$$
S_{\text {heat }}=h_{\text {conv }} A_{h t}\left(T_{\text {wall }}-T\right) \text {, }
$$

where $A_{h t}$ is a geometrical parameter that represents the surface over which the heat transfer occurs between the fluid at temperature $T$, and the surface $A_{h t}$ at temperature $T_{\text {wall }}$. The convective heat transfer coefficient $h_{\text {conv }}$ is evaluated accordingly to the Dittus-Boelter's equation for forced convection turbulent flow:

$$
N u_{D}=0.024 \operatorname{Re}_{D}^{n} \operatorname{Pr}^{m}
$$

Where the exponent $n=0.8$ and $m=0.3$ if the fluid is cooled or $m=0.4$ otherwise.

\section{Momentum Balances at the Vaneless Diffuser}

Resorting to the weighting process described in the solution procedure of the impeller outlet port, the absolute velocity at the port of the vaneless diffuser is then calculated still referring to the area overlap.

In the diffuser region, the solution of the momentum conservation equations is solved referring to the absolute reference system and does not contain any source term contribution. The flow in this region should guarantee the conservation of the angular momentum. Hence, the tangential component of the absolute velocity is also assigned to the port belonging to the vaneless diffuser, instead of only the component directed as the port normal. This effect results in the solution of two equations referring to the schematic in Figure 12:

- The free vortex equation

$$
v_{\text {tang }} \cdot r=\text { constant }
$$

- the momentum conservation along the radial direction 
FIGURE 12 Decomposition of the momentum conservation into radial and tangential components. The free vortex flow assumption has been introduced along tangential component.

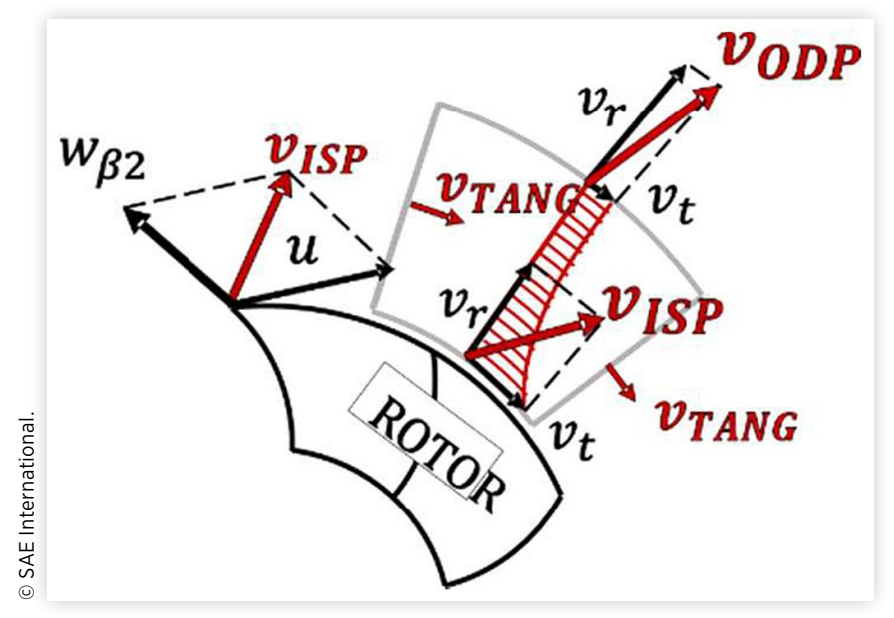

$$
\begin{aligned}
\left(\rho \vec{v}_{\text {rad }} A\right)_{\text {port }}^{t+\frac{1}{2}}= & \left(\rho \vec{v}_{\text {rad }} A\right)_{\text {port }}^{t-\frac{1}{2}} \\
& +\frac{\Delta t}{\Delta L} A_{\text {port }}\left[\left(p+\rho v_{\text {rad }}^{2}\right)_{L}^{t}-\left(p+\rho v_{\text {rad }}^{2}\right)_{R}^{t}\right]+S_{M},
\end{aligned}
$$

\section{Cell Momentumem Calculation}

In all the cells, after having solved the port momentum equation, the energy and the mass conservation equations, the cell momentum is calculated on the basis of the momentum of the ports that are connected to each cell. The momentum of each port has a direction in the space, since it is directed as the normal to the port, and for this reason the result will be a cell momentum arbitrarily oriented in the space. Each port contribute to the calculation of the cell momentum with only half of its momentum, the one that is associated with the distance between the cell center and the face center:

$$
(\rho U)_{\text {cell }}^{t+1}=\frac{1}{2} \sum_{p=1}^{N_{\text {ports }}}(\rho U A)_{p}^{t+1} \Delta L
$$

Since at this level there is no modeling assumption that must be included, but it is just a matter of a weighted average on the port characteristic length, no distinction between the cells (rotor, diffuser or volute) is done.

\section{Results}

The quasi 3D model was then applied to the simulation of the compressor considering the presence of the heat transfer. No sensible change to the total to total pressure ratio can be experimentally observed as reported in Figure $4[\underline{7}, \underline{8}]$ and a similar trend can be observed in the calculations. As can be seen in Figure 13 the effect of the heat transfer from the turbine does
FIGURE 13 Comparison between computed and measured pressure ratio for different temperature levels of the gas temperature at the inlet of the turbine.

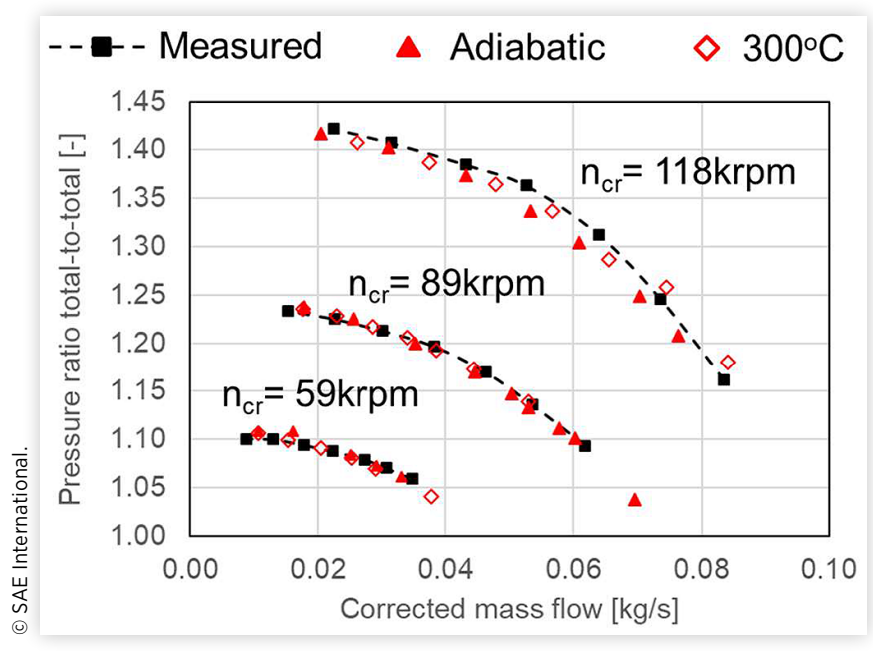

FIGURE 14 Comparison between total to total efficiency calculated (continuous line) and measured (dashed line) for different temperature level of the gas at the inlet of the turbine.

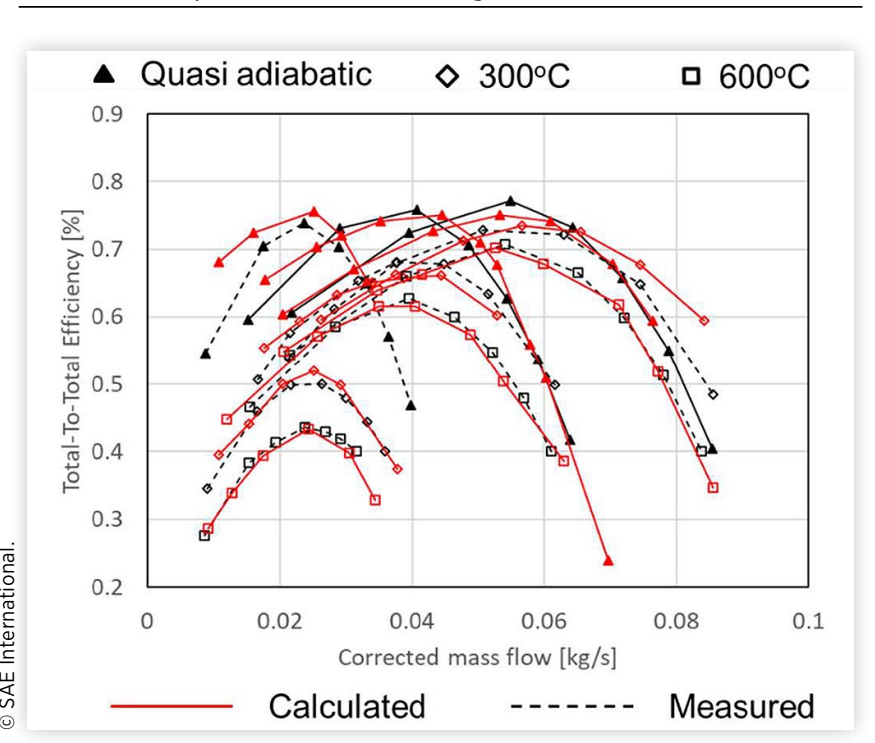

not affect the pressure ratio delivered by the fluid machine for different rotational speed.

At numerical level, the heat flux experimentally evaluated has been imposed as a boundary condition, varying the wall temperature of the rotor channel to match, or approximate, the measured heat flux. Only the temperature of the rotor channel has been set following this procedure, whereas the volute temperature has been imposed on the basis of measured surface temperature [ $\underline{8}, \underline{9}]$. In terms of efficiency, the expected decrease of the compressor performance can be observed also numerically. Figure 14 shows that the model predicts accurately the decay of the efficiency both as a function of the turbine inlet temperature and of the rotational speed for two different levels of turbine inlet temperature. It can be observed that the impact of heat transfer appears to be less important at high revolution speed since the heat power transferred to 
FIGURE 15 Comparison between the heat flux experimentally estimated and the calculated one for the turbine inlet temperature of $80^{\circ} \mathrm{C}$.

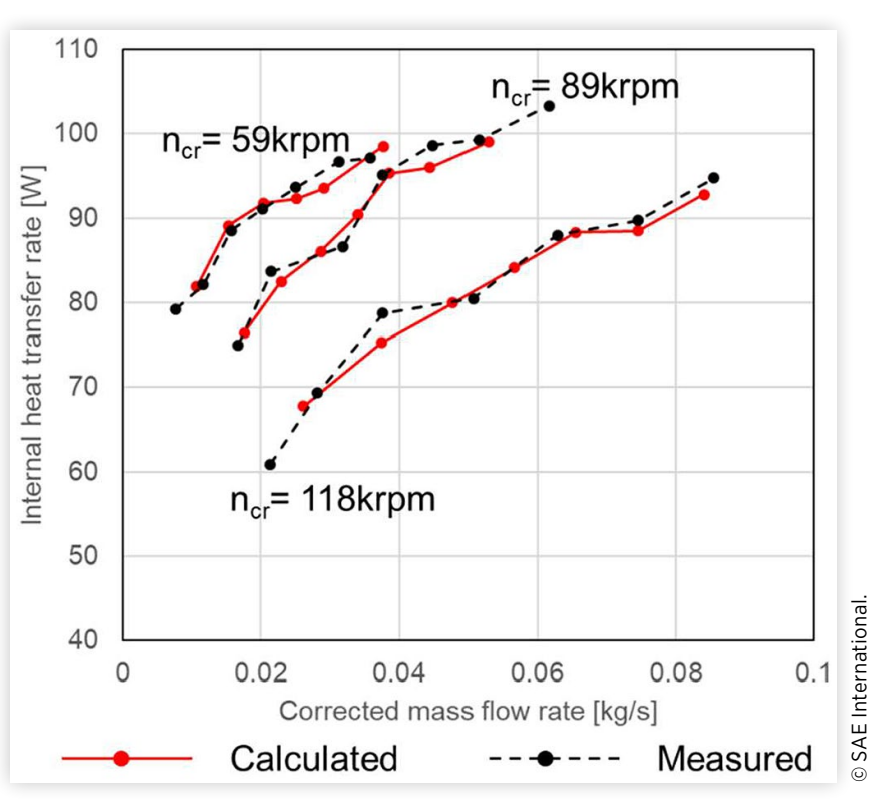

the gas decreases with respect to the increase of mechanical power. As shown in Figure 15, measurements indicate that at fixed mass flow the heat power decreases with the revolution speed as a consequence of the complex heat balance of the whole turbocharger group, which includes the contribution of the oil and of the heat transfer to the environment.

Since the heat transfer in the model has been carried out imposing the rotor blade temperature, the code can also be used to estimate this temperature. In Figure 15, it can be observed that the heat flux introduced by means of the heat transfer along the blade channel is in agreement with the one estimated experimentally following this procedure.

FIGURE 16 Calculated rotor blade temperature for different revolution speeds [9]].

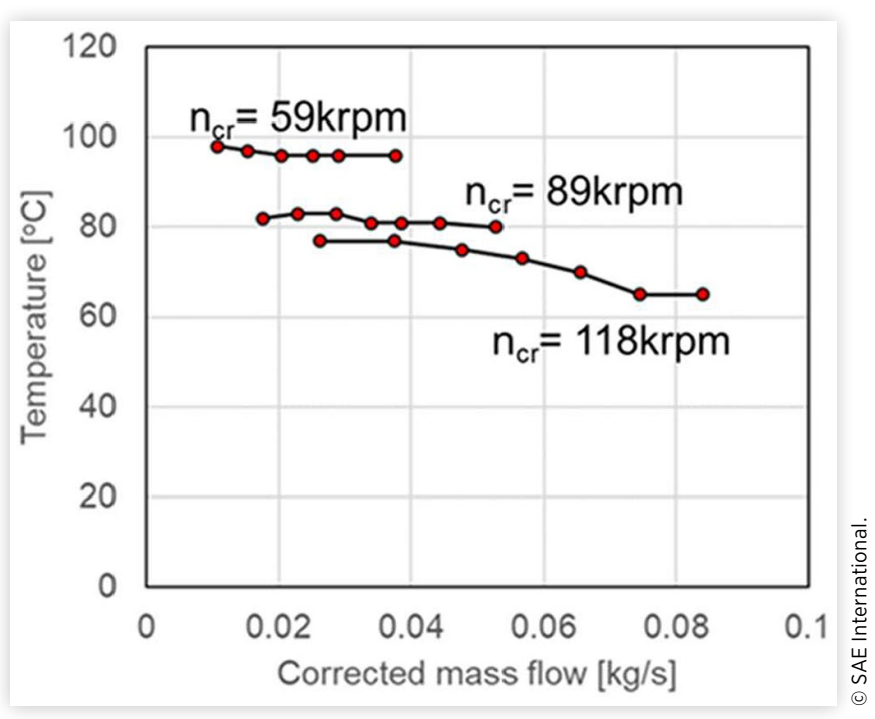

Additionally, Figure 16 shows that the temperature of the rotor blade decreases with the compressor rotational speed and it shows a weak dependence with the gas mass flow for a constant iso-speed level. The decrease of blade temperature with the speed of the turbocharger can be explained with the rise of the convective heat transfer coefficient.

\section{Conclusions}

This study presents the results of an experimental and numerical analysis of a turbocharger compressor in steady operating conditions, with special focus to the measurement of the total to total isentropic efficiency in the presence of turbocharger internal heat transfer. Starting from previous investigations on the effect of different working temperatures conditions of heat transfer phenomena, a model previously developed by the University of Genoa for the correction of compressor steady flow maps was validated by the quasi-3D numerical model used to simulate the compressor both in adiabatic and diabatic condition.

The quasi-3D method has been extended and applied to model a compressor accounting for the heat transfer phenomena between the fluid and the compressor's walls. This approach is a map-less method, based on the 3D reconstruction of the geometry with the minimum number of geometrical data required. To extend the model to account for the heat interaction, the temperature of the volute has been measured by means of a digital infrared camera at the University of Genoa and imposed as a boundary condition in the numerical framework, while the temperature of the impeller has been inferred from the experimental heat flux coming from the turbine. The numerical results show that the model has been capable to reproduce the effect of the heat on compressor's performances. In agreement with experimental measurements, the calculated total to total pressure ratio curves are not affected by diabatic conditions and overlap on the adiabatic ones. Conversely, total to total efficiency exhibit a drop, that is especially noticeable at low rotational speeds. Moreover, the efficiency increases with the revolution due to the reduced weight that this contribution has, if compared to the mechanical power transferred. For all tested conditions, the quasi-3D model has been able to predict the effect of heat transfer on the measured diabatic total to total efficiency with a satisfactory agreement, showing a potential of the model in the prediction of turbochargers performances without resorting to predetermined maps.

\section{References}

1. Bandel, W.,Fraidl, G.K.,Kapus, P.E., andSikinger, H., “The Turbocharged GDI Engine: Boosted Synergies for High Fuel Economy Plus Ultra-Low Emission," SAE Technical Paper 2006-01-1266, 2006, https://doi.org/10.4271/2006-01-1266.

2. Luisi, S.,Doria, V.,Stroppiana, A.,Millo, F., andMirzaeian, M., "Experimental Investigation on Early and Late Intake Valve Closures for Knock Mitigation through Miller Cycle in 
a Downsized Turbocharged Engine," SAE Technical Paper 2015-01-0760, 2015, https://doi.org/10.4271/2015-01-0760.

3. Serrano, J.R.,Olmeda, P.,Arnau, F.J.,Dombrovsky, A., andSmith, L., "Turbocharger Heat Transfer and Mechanical Losses Influence in Predicting Engines Performance by Using One-Dimensional Simulation Codes," Energy 86:204218, 2015, doi:10.1016/j.energy.2015.03.130.

4. Casey, M.V. andFesich, T.M., "The Efficiency of Turbocharger Compressors with Diabatic Flows," Journal of Engineering for Gas Turbines and Power 132:072302, 2010.

5. Romagnoli, A. andMartinez-Botas, R., "Heat Transfer Analysis in a Turbocharger Turbine: An Experimental and Computational Evaluation," Applied Thermal Engineering 38:58-77, 2012.

6. Chesse, P.,Chalet, D., andTauxia, X., "Impact of the Heat Transfer on the Performance Calculations of Automotive Turbocharger Compressor," Oil \& Gas Science and Technology, Rev. IFP Energies Nouvelles 66(5):791-800, 2011, doi:10.2561/ogst/2011129.

7. Marelli, S.,Marmorato, G.,Capobianco, M., andRinaldi, A., "Heat Transfer Effects on Performance Map of a Turbocharger Compressor for Automotive Application," SAE Technical Paper 2015-01-1287, 2015, https://doi. org/10.4271/2015-01-1287.

8. Marelli, S.,Marmorato, G., andCapobianco, M., "Evaluation of Heat Transfer Effects in Small Turbochargers by Theoretical Model and Its Experimental Validation," Energy, Elsevier, 2016, doi:10.1016/j.energy.2016.06.067.

9. Tanda, G.,Marelli, S.,Marmorato, G., andCapobianco, M., "An Experimental Investigation of Internal Heat Transfer in an Automotive Turbocharger Compressor," Applied Energy 193:531-539, 2017, http://dx.doi.org/10.1016/j. apenergy.2017.02.053.

10. Torre, A.D.,Montenegro, G.,Cerri, T., andOnorati, A., "A 1D/ Quasi-3D Coupled Model for the Simulation of I.C. Engines: Development and Application of an Automatic Cell-Network Generator," SAE Int. J. Engines 10(2):471-482, 2017.

11. Montenegro, G.,Della Torre, A.,Cerri, T.,Lenzi, G.et al., "Fluid Dynamic and Acoustic Optimization Methodology of a Motorbike Intake Airbox Using Multilevel Numerical CFD Models and Experimental Validation Tests," SAE Int. J. Engines 6(3):1731-1744, 2013, https://doi.org/10.4271/201324-0070.

12. Montenegro, G.,Della Torre, A.,Onorati, A., andFairbrother, R. A Nonlinear Quasi-3D Approach for the Modeling of Mufflers with Perforated Elements and Sound-Absorbing Material (2013) Advances in Acoustics and Vibration, art no. 546120 .
13. Montenegro, G.,Onorati, A., andDella Torre, A., "The Prediction of Silencer Acoustical Performances by 1D, 1D3D and Quasi-3D Non-Linear Approaches," Computers and Fluids 71:208-223, 2013.

14. Montenegro, G.,Tamborski, M.,Della Torre, A.,Onorati, A.et al., "Development and Application of a Quasi-3D Model for the Simulation of Radial Compressors of Turbochargers for Internal Combustion Engines," SAE Technical Paper 201924-0187, 2019, 2019, https://doi.org/10.4271/2019-24-0187.

15. Marelli, S. andCapobianco, M., "Measurement of Instantaneous Fluid Dynamic Parameters in Automotive Turbocharging Circuit," SAE Technical Paper 2009-24-0124, 2009, 2009, https://doi.org/10.4271/2009-24-0124.

16. Marelli, S.,Misley, A.,Taylor, A.,Silvestri, P.et al., "Experimental Investigation on Surge Phenomena in an Automotive Turbocharger Compressor," SAE Technical Paper 2018-01-0976, 2018, https://doi.org/10.4271/2018-01$\underline{0976}$.

17. Eynon, P.A. andWhitfield, A., "Pressure Recovery in a Turbocharger Compressor Volute," Proceedings of the Institution of Mechanical Engineers, Part A: Journal of Power and Energy 599-610, 2000.

18. Sovran, G. andKlomp, E.D., "Experimentally Determined Optimum Geometries for Rectilinear Diffusers with Rectangular Conical or Annular Cross Section," Fluid Mechanics of Internal Flow, Elsevier, 270-319, 1967.

19. Sirakov, B. andCasey, M., "Evaluation of Heat Transfer Effects on Turbocharger Performance," J of Turbomachinery, 2013, doi:10.1115/1.4006608.

20. Daily, J.W. andNece, R.E., "Chamber Dimension Effects on Induced Flow and Frictional Resistance of Enclosed Rotating Disks," Journal of Basic Engineering 82(1):217-230, 1960, doi:10.1115/1.3662532.

21. Swamee, P.K. andJain, A.K., "Explicit Equations for PipeLow Problems," J. Hydraulic Div. Proc. ASCE 657-664, May 1976.

\section{Contact Information}

\author{
Silvia Marelli (Associate Professor) \\ DIME, University of Genoa, Genoa, Italy \\ silvia.marelli@unige.it
}

Gianluca Montenegro (Associate Professor)

Department of Energy, Politecnico di Milano, Italy gianluca.montenegro@polimi.it

(C) 2020 SAE International. All rights reserved. No part of this publication may be reproduced, stored in a retrieval system, or transmitted, in any form or by any means, electronic, mechanical, photocopying, recording, or otherwise, without the prior written permission of SAE International. 